This item was submitted to Loughborough's Research Repository by the author.

Items in Figshare are protected by copyright, with all rights reserved, unless otherwise indicated.

\title{
Using a model of the performance measures in Soft Systems Methodology (SSM) to take action: a case study in health care
}

PLEASE CITE THE PUBLISHED VERSION

http://dx.doi.org/10.1057/jors.2012.21

\section{PUBLISHER}

(C) Palgrave Macmillan for the OR Society

\section{VERSION}

AM (Accepted Manuscript)

\section{LICENCE}

CC BY-NC-ND 4.0

\section{REPOSITORY RECORD}

Kotiadis, Katherine, Antuela A. Tako, Etienne A.J.A. Rouwette, Christos Vasilakis, J. Brennan, P. Gandhi, H. Wegstapel, F. Sagias, and P. Webb. 2019. "Using a Model of the Performance Measures in Soft Systems Methodology (SSM) to Take Action: A Case Study in Health Care". figshare. https://hdl.handle.net/2134/14616. 
This item was submitted to Loughborough's Institutional Repository (https://dspace.lboro.ac.uk/) by the author and is made available under the following Creative Commons Licence conditions.

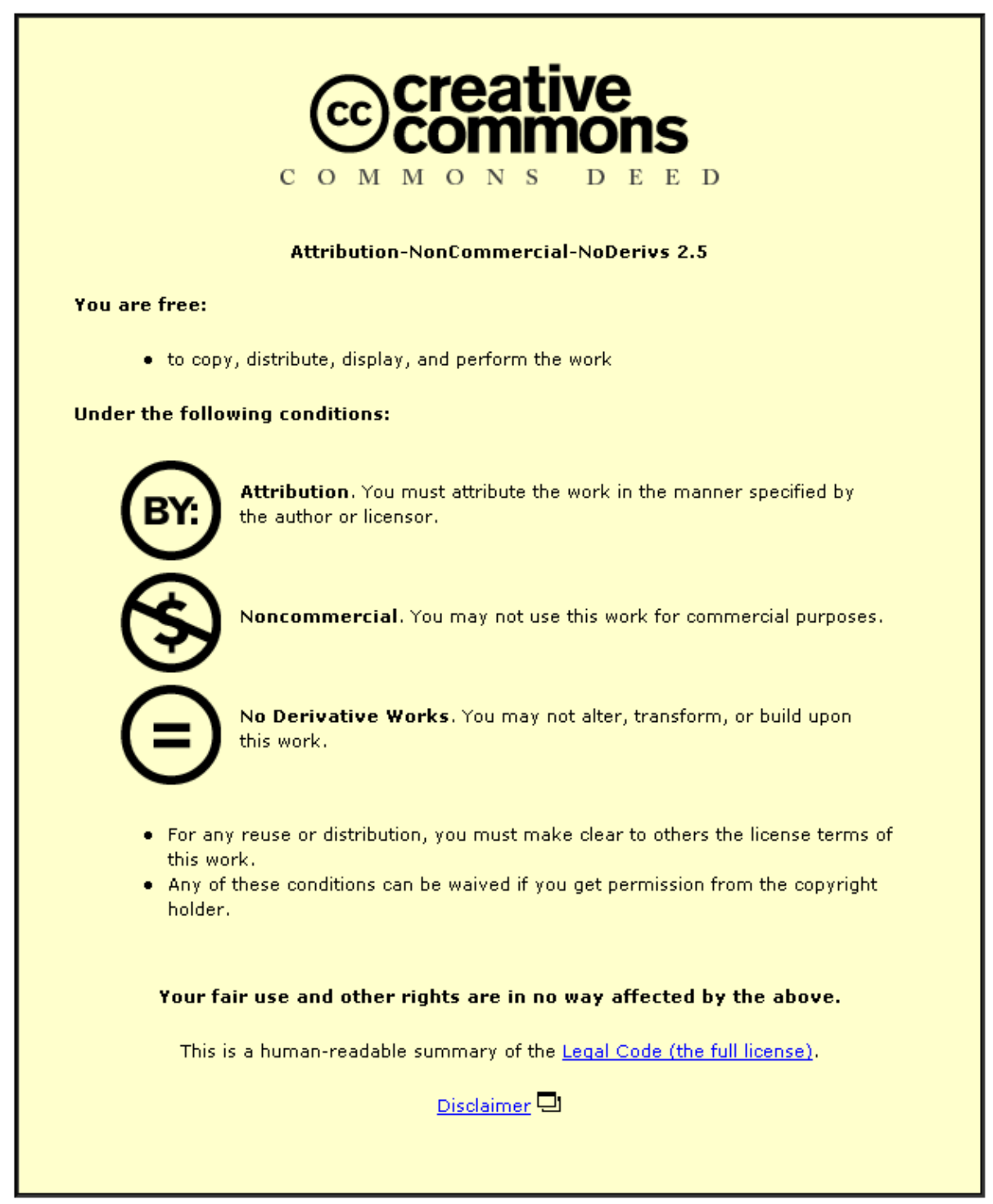

For the full text of this licence, please go to: http://creativecommons.org/licenses/by-nc-nd/2.5/ 


\section{Using a model of the performance measures in Soft Systems Methodology (SSM) to take action: a case study in health care}

Kotiadis $\mathrm{K}^{1}$, Tako $\mathrm{A}^{2}$, Rouwette $\mathrm{E}^{3}$, Vasilakis $\mathrm{C}^{4}$, Brennan $\mathrm{J}^{5}$, Gandhi $\mathrm{P}^{5}$, Wegstapel $\mathrm{H}^{5}$, Sagias $\mathrm{F}^{5}$, Webb $\mathrm{P}^{5}$

${ }^{1}$ Warwick Business School, University of Warwick, Coventry CV4 7AL, UK

${ }^{2}$ School of Business and Economics, Loughborough University, LE11 3TU, UK

${ }^{3}$ Instititute for Management Research, Radboud University Nijmegen, Nijmegen, 6500 HK, The Netherlands

${ }^{4}$ Clinical Operational Research Unit, University College London, London, WC1H OBT, UK

${ }^{5}$ Medway Maritime Hospital, Gillingham ME7 5NY, UK

Keywords: SSM, Measures of Performance, Performance Measurement Model, participative, facilitation, health care, multidisciplinary teams

Abstract:

This paper uses a case study of a multi-disciplinary colorectal cancer team in health care to explain how a model of performance measures can lead to debate and action in Soft System Methodology (SSM). This study gives a greater emphasis and role to the performance measures than currently given in typical SSM studies. Currently the concept of performance measurement in SSM is in the form of a set of criteria used to judge the performance of the SSM model (the purposeful activity model). These performance criteria are definitions of efficacy, efficiency, effectiveness, ethicality and elegance. However, the use of performance measures within SSM is not clear and therefore criticized by some as nebulous. This paper uses a case study to explain how to involve the stakeholders in deriving a performance measurement model (PMM) which is a more detailed expansion of the performance criteria. The paper concludes with some reflections about how the PMM can fit in the SSM cycle, with two modes of practice put forward. 
Journal of the Operational Research Society (2013) 64, 125-137.

doi: 10.1057/jors.2012.21; published online 18 April 2012

\section{Introduction}

This paper uses a case study of a multidisciplinary team in health care to put forward the idea of using a performance measurement model (PMM) as part of Soft Systems Methodology's (SSM) action research cycle. Debating the situation using the PMM - a more detailed exploration of the performance measures in SSM - can have an impact on action separate from and in addition to the other activities in SSM, thus enhancing SSM's action research cycle that underpins the approach. The use of a PMM in an SSM intervention provides a more detailed expansion to the measures of performance, which are efficacy, efficiency, effectiveness, ethicality and elegance. The measures of performance are criteria, used in SSM, by which the performance of the system as a whole will be judged (Checkland, 1999b). Despite the importance placed by Checkland on these measures of performance they are still considered by some as nebulous (Bergvall-Kareborn and Grahn, 1996). However, some recent studies involving SSM have given these performance measures a greater role (Kotiadis 2007; Mingers et al. 2009) in the SSM intervention signalling the need for further research and clarity and the opportunity for these measures to play a more central role in the SSM cycle. More specifically, Kotiadis (2007) introduced the idea of extending the SSM performance measures into a performance measurement model. The PMM was derived as part of a study taking a multimethodology approach mixing SSM and discrete event simulation in order to obtain the simulation study objectives. Reflecting on the outcomes of this study, it was felt that the PMM could be useful in debating the problematic situation in standalone participative SSM studies.

The aim of this paper is to describe how the measures of performance can be extended to form a PMM and how this in turn can be used in practice to support an SSM intervention. Eden and Ackermann (2006) and Checkland (2006) suggest that a useful way to increase transferability of methods is to offer more in-depth case descriptions of real life projects. Therefore, in this paper, the process of arriving at a PMM is explained through a real-life case study in health care involving a UK multidisciplinary team (MDT). The MDT meetings provide a weekly forum for health care professionals from different clinical disciplines (e.g. oncology, radiology, histopathology etc) to discuss individual patients and to make collective decisions regarding their treatment. Benefits are considered to include increased changes of accurate diagnosis and staging, better treatment plans decided by a group of experts, and 
J ournal of the Operational Research Society (2013) 64, 125- 137.

doi: 10.1057/jors.2012.21; published online 18 April 2012

better coordination and continuity of care (Carter et al, 2003). MDTs deliver specialist care to patients suffering from a particular type of cancer, for instance lung cancer. The case study described here focuses on an evaluation of the function of a colorectal cancer MDT in Kent in the UK.

The key contributions of this paper are:

First of all, it shows how a more in depth and extended version of SSM's performance measures tool, called the performance measurement model (PMM), can be constructed participatively with the stakeholders during a workshop. Thus, it furthers the debate on how to use the performance measures that are currently considered as nebulous to help the process of debating the problematic situation and identifying action to be taken as part of an SSM intervention. In addition, we use a measurement on the actions before and after the PMM development to substantiate that participative building has positive outcomes such as consensus and agreement in the decision making process and learning. The paper also provides two modes of practice on how the performance measurement model can fit in the SSM cycle that may be helpful to others.

Secondly, it provides a description of a real SSM case study in health care taking place over a period of three years. The initial intervention, mainly a facilitated workshop, took place in 2006 where the notional system of interest was defined and subsequently implemented over the following three years. In 2009 the follow up intervention, which also took the form of a facilitated workshop, focused on the evaluation of this system of interest.

The paper is divided into three further sections. The first section explores some key SSM concepts and reports on existing studies that contribute to the practice of performance measurement in SSM. The second section describes the case study and is structured around the events taking place between the first and second workshop. The final section provides a discussion around the evaluation of SSM interventions with two modes of practice being put forward for integrating the PMM in the SSM cycle.

\section{Performance measurement in SSM}

SSM is both a problem structuring approach and an organised learning system that deals with problematical situations where there may not be an obvious problem or solution 
J ournal of the Operational Research Society (2013) 64, 125- 137.

doi: 10.1057/jors.2012.21; published online 18 April 2012

(Checkland, 1999a). The ultimate aim of SSM is to enable the stakeholder(s) involved in the intervention to learn about the problematic situation and based on that to decide on action that will bring about improvement. Indeed SSM falls in the category of action research (Checkland, 1999b), as opposed to the traditional positivist and interpretivist views of science, whereby the analyst intervenes in the organisation studied and works with organisational members on a situation of interest to them (Lewin, 1946). Action research, and by association SSM, is a process of enquiry that can be represented as a repeating cycle (loop) taking the form of identifying problematic situation, planning, acting and evaluation. The loop continues if the process of evaluation leads to the identification of a new problem.

SSM was conceptualised in the seventies and over the years was refined to form the four main activities version in the 1990s consisting of the following stages (Checkland, 1999b):

1. Finding out about a problem situation, including culturally/politically;

2. Formulate some relevant purposeful activity models;

3. Debating the situation, using the models, seeking from that debate both:

Changes which could improve the situation and are regarded as both desirable and (culturally) feasible, and

The accommodations between conflicting interests which will enable action-toimprove to be taken;

4. Taking action in the situation to bring about improvement.

The stages described above form the methodology that can be thought of as the principles of the method. The stages are supported by a set of SSM tools that, as the approach, are generic in nature and can be applied to any context. Each of the stages and supporting tools will be next briefly described based on guidelines provided by Checkland (1999b) and the authors' experience of SSM in practice.

\subsection{Stage 1 - Findling out about the problem situation}

The first SSM stage, to find out about the problem situation either with the stakeholders or through observation of the stakeholders and their system, is supported by rich picture drawing (tool to record important relationships within the situation) and/or analysis one, two and three (tool used to undertake role, social and political analysis) (Checkland, 1999b). 
J ournal of the Operational Research Society (2013) 64, 125- 137.

doi: 10.1057/jors.2012.21; published online 18 April 2012

\subsection{Stage 2 - Formulate some relevant purposeful activity models}

The second stage is about constructing, with the input of stakeholders involved in the intervention, the SSM model, which is commonly known as the Purposeful Activity Model (PAM). Purposeful activity models are 'devices to stimulate, feed and structure debate' (Checkland 1999b, pp A21) and are only relevant to the individual or group involved in their construction. The construction of the PAM can begin by defining one or more systems that are considered relevant to exploring the problematic situation. The tools assisting this stage include CATWOE, root definition and measures of performance. The CATWOE is a mnemonic (formed of the first letter of each element) to define customer (s), actor (s), transformation process (or input and output of the process), Weltanschauung (or worldview), owner(s) and environmental constraints. The root definition provides structure to the CATWOE definitions and concisely explains the purpose of the system studied following the format of do $P$ by $Q$ in order to achieve $R$, also known as $P Q R$. The root definition and in particular the transformation process are central to the construction of the PAM. Indeed, the PAM largely represents the minimum activities to enable the transformation to take place. A generic description of the PAM can be seen in figure 1 . The measures of performance or Es are also defined in this stage. They are criteria used to define and monitor the performance of the system represented in the PAM in terms of efficacy, efficiency, effectiveness and if appropriate these measures can be extended to include ethicality and elegance. In the existing SSM methodology these definitions precede the development of the PAM. 


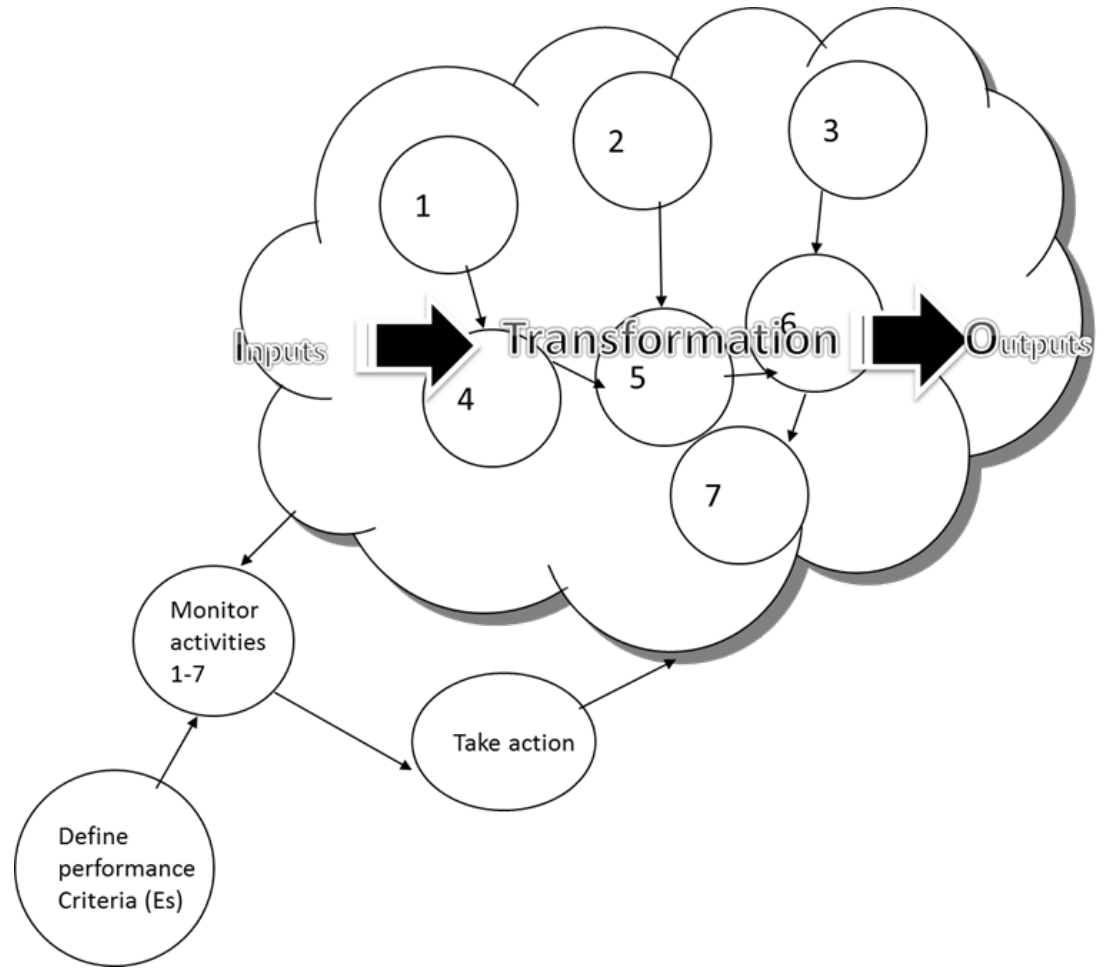

Figure 1 SSM's Purposeful Activity Model

The measures of performance (also known as performance criteria) are clearly meant to be an important part of the process of discussing the purposeful activity models even if the system is only notional. Checkland explains 'it is necessary to define the criteria by which the performance of the system as a whole will be judged' (1999b, pp A25). The measures of performance were introduced to provide an evaluation element to the PAM during stakeholder discussions. Checkland et al. (1990) originally established the individual criteria by exploring the questions of how could the transformation process fail or be regarded as unsuccessful? Further exploration to these questions led to the following performance measures currently included in the SSM toolset:

Efficacy - is the transformation, represented by the activities in the PAM, producing the output?

Efficiency - are the minimum resources used to obtain the output of the transformation process?

Effectiveness - does the transformation meet the longer term goal(s) as put forward in the Weltanschauung? 
J ournal of the Operational Research Society (2013) 64, 125- 137.

doi: 10.1057/jors.2012.21; published online 18 April 2012

Ethics -is the transformation morally correct?

Elegance - is the transformation aesthetically pleasing?

As the first three performance measures or criteria are used in most cases and the latter two are considered to be less frequently called upon, the performance measures are typically known as the 3Es. The performance measures in SSM are central to this paper's contribution so we will return to explore the relevant literature once we have explained the remaining stages of the SSM methodology.

\subsection{Stage 3 and 4 - Debate the situation and Take action}

In the third stage the individual or group involved in the intervention debate the situation comparing the PAM to their perceptions of the existing situation. The performance measures, defined in the second stage are used in this stage (third) to assist the process of debating the situation of interest using the PAM. However, the relationship between the measures of performance and PAM could be described as indirect. Although the definitions of the measures of performance already take the form of questions that relate to key aspects of the situation of interest, such as the transformation, the activities in the PAM may not fully support the line of questioning. This is the likely reason that this aspect of SSM is considered as vague (Bergvall-Kareborn and Grahn, 1996). The individuals participating in the SSM intervention are often asked at this stage to consider each activity in the PAM and the relationships between activities in terms of whether they exist or could be improved. In figure 1 the activities are represented by the numbered circles, which in practice would include text, and the relationships are represented through the connecting arrows. The aim of the debate is to seek both changes which could improve the situation and are regarded as both desirable and (culturally) feasible, and accommodations between conflicting interests which will enable action-to-improve to be taken. Taking action may involve structural, process or attitude change or can even be about making sense (learning) of a complex situation (Checkland, 1999b).

\subsection{Studies extending the measures of performance}

There is a vast literature on performance measurement, with some key papers referring to the strategic role of performance (Kaplan and Norton, 2001), its role in public policy (Brignall and Model, 2000) and the role of OR methods in developing performance measures 
J ournal of the Operational Research Society (2013) 64, 125- 137.

doi: 10.1057/jors.2012.21; published online 18 April 2012

(Lohman et al, 2004). As this paper considers the use of performance measures in SSM, we limit the discussion on studies that extend the use of performance measurement in this context. Reviewing the large literature on performance measurement is considered outside of the scope of this paper. Three studies contribute to the debate about performance measures in SSM, particularly in terms of attempting to provide transparency in the process of using them.

Bergvall-Kareborn and Grahn (1996) discussed the shortfalls of the current list of performance measures (Es) because it is not clear: a) why these particular measures were chosen, b) how they should be used, c) what they exactly mean, d) what they should relate to and e) how one knows whether they are achieved and suggested expanding the range of criteria. The study expanded the range of criteria and illustrated how the criteria contribute to the analysis and understanding of a shipping catastrophe. It should be noted that the authors make it clear they were never actually involved with the real problem situation and all information in illustrating the example was obtained from the media. Although they provided an in depth analysis of the performance measures, or indicators as they call them, their process may not lead to similar results in other real life situations. The contribution of their study is to introduce a wider range of performance criteria/indicators, in terms of breadth rather than depth.

Kotiadis (2007) introduced the idea of extending SSM's measures of performance into a performance measurement model (PMM) to obtain the simulation study objectives in a study of an intermediate care system that employed SSM and discrete event simulation multi-methodology. In this study, having developed a PAM, the SSM's measures of performance were further broken down into a number of activities and appended below the monitoring activities part of the PAM, and the extension was called a PMM. A generic structure of the PMM can be seen in figure 2 demonstrating the structure of the PMM. The reader should note the difference of the monitoring activities at the bottom of figures 1 and 2. The performance measurement aspect introduced, fits with the SSM philosophy to design an 'agreeable and desirable' (in this case the PMM) model mapping on to existing and new structures (activities), and subsequently to use that PMM model and decide if any action should be taken to bring about improvements to the performance of the system of interest (represented by the PAM). The difference of this study (Kotiadis, 2007) from other 
J ournal of the Operational Research Society (2013) 64, 125- 137.

doi: 10.1057/jors.2012.21; published online 18 April 2012

traditional SSM studies lies in the fact that the construction of the PMM is used to reflect on how each activity, supporting the transformation process in the PAM, can be evaluated. However, the process of arriving at the PMM was not done in a participative way in a workshop environment involving stakeholders.

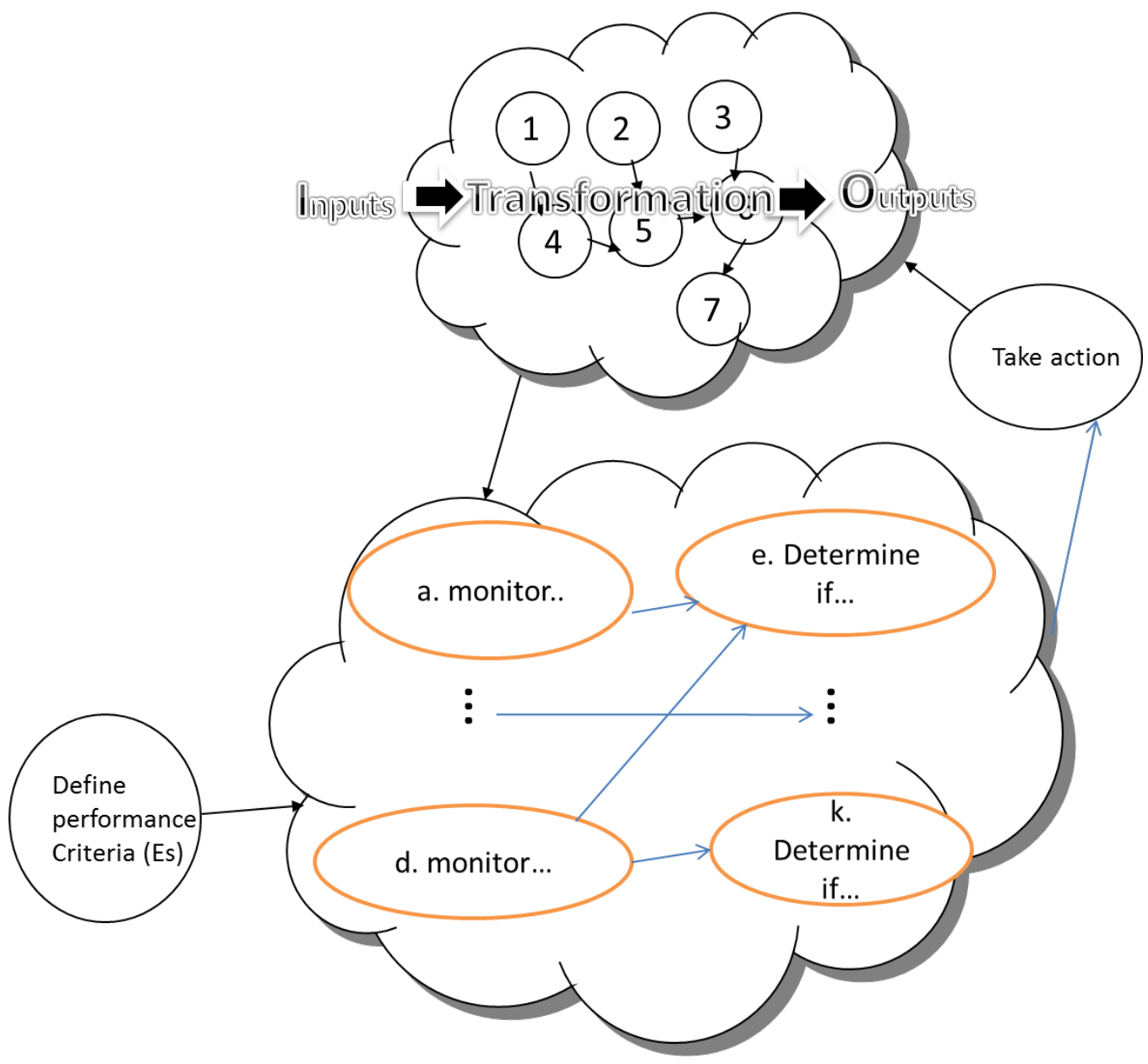

Figure 2 The relationship between the PAM and PMM

Mingers et al. (2009) combined SSM with data envelopment analysis (DEA) in an evaluation study of the Chinese Academy of Sciences research institutes. DEA is typically associated with the term 'performance measurement' as it measures efficiency of decision making units. The study linked DEA to the transformation process and the performance measures of SSM. Essentially Checkland's (1990) Es were broken down into more specific measures of performance that could be used to obtain a more detailed account of the performance indicators to be used in a DEA model. Mingers et al. (2009) paper also demonstrated that expanding the SSM performance measures is a useful activity. 
J ournal of the Operational Research Society (2013) 64, 125- 137.

doi: 10.1057/jors.2012.21; published online 18 April 2012

Although all three studies focus on Checkland's (1990) measures of performance and expand them either in depth or breadth, they all fall short of providing an approach that can be used readily in any context by a group of stakeholders that are only using SSM. Furthermore, the existing literature provides few practical links between these broad definitions of the Es and using them to stimulate debate among the stakeholders. There is no guidance on how a user of the methodology, particularly a novice, can establish through discussion whether the transformation process in the purposeful activity model is effective, efficient or efficacious (and perhaps also elegant and ethical), to then lead to action to be taken as step 4 of the methodology. This certainly means that there is no transparency in that part of the process, which is something recent papers identify as one of the key challenges for continued success of model-driven methods (Checkland, 2006; Eden and Ackermann, 2006; Westcombe et al, 2006). This paper aims to provide transparency in the process of using the measures of performance, by extending them in performance measurement model, which in turn can be used to identify action to be taken.

\section{The Case Study - the colorectal multidisciplinary team}

The case study described hereon is about an SSM intervention, undertaken in two parts, approximately three years apart, one in 2006 and the following one in 2009. In 2006 a multidisciplinary colorectal cancer team of surgeons based in an NHS trust in the south of England approached two operational researchers to explore their multidisciplinary team (MDT) function in light of an upcoming evaluation. Multidisciplinary medical teams are recognised as central decision points in the patient pathway, and the quality of information sharing in these meetings is an important factor in creating beneficiary outcomes for patients (Kane and Luz, 2011). For a more detailed explanation of the activities undertaken in MDT meetings, interested readers are referred to a recent study by Kane and Luz (2011). The aim of the study in 2006 was to determine if and what action should be taken to bring about improvements to the MDT meetings and their organisation. The SSM intervention in 2006 involved observations of the MDT meetings, interviews with members of the team and a workshop. In 2009 the analysts approached the MDT again to find out if and what type of action had been taken since the first workshop and to explore whether a performance monitoring element, that would take the form of a PMM, was desirable now that the system 
J ournal of the Operational Research Society (2013) 64, 125- 137.

doi: 10.1057/jors.2012.21; published online 18 April 2012

was more established. The second part of the SSM intervention, which took place in 2009 involved an observation and a workshop. The following sections provide an overview of the process and outputs of each intervention starting with the earliest one in 2006.

\subsection{Improving the MDT meetings (Workshop 1)}

\subsubsection{Background information}

The colorectal multidisciplinary team (MDT) meetings were held weekly in the same venue with a permanent core membership consisting of the colorectal consultant surgeons (four in 2006), a histopathologist, an oncologist, a radiologist, nurse practitioners, MDT coordinators and other junior doctors belonging to the colorectal firms (each consultant represents a firm). The MDT meeting operates as a pull system in which the coordinators have the responsibility of creating the patient list for each multidisciplinary meeting. For each patient, information such as the case notes and the results from all clinical investigations (for example test results and imaging) are assembled. The patient selection process is largely dependent on the patients' time in the system and the availability of the results of the investigations. It is important that patients progress through the system in a timely fashion so the trust meets waiting time targets set by the government. Each patient breeching a target means that the trust incurs a fine.

In 2006 the consultant surgeons expressed some concerns about their MDT function and suggested areas of improvement such as the availability of the patients' results and the equipment available in the room. Preliminary investigations revealed a lack of relevant documentation and a fragmented understanding of the MDT by its membership. It soon emerged that it was important to arrive at a common description of the MDT and its function and so it was decided to organise a facilitated workshop for this task. SSM was considered suitable for use as it has tools that can be used at arriving at a shared understanding while accounting for multiple stakeholder involvement and diverse views. The following section provides a brief description of the workshop.

\subsection{Workshop 1 (2006)}

The analysts assembled the information extracted from observations of the MDT and interviews with the team members into preliminary SSM definitions (CATWOE, Root 
Journal of the Operational Research Society (2013) 64, 125-137.

doi: 10.1057/jors.2012.21; published online 18 April 2012

definition) to be used in the workshop to aid the process of developing models of the MDT at the strategic and operational level. In this paper we will only reflect on the operational function because at the strategic level one of the consultants (the lead clinician) was the owner and main actor (we discovered this during the workshop) making the remaining stakeholders surplus to requirement in discussions to take action. However, the group as a whole had ownership of the MDT at the operational level and therefore provided more opportunities for subsequent action (implementation of change).

Table 1 The CATWOE definition for the MDT meetings

\begin{tabular}{|c|c|}
\hline & Operational function definitions \\
\hline Customer & Patients \\
\hline Actor & MDT participants \\
\hline Transformation Process & $\begin{array}{l}\text { The need for multidisciplinary and patient-centred diagnosis, } \\
\text { treatment and care plan is met by presenting, evaluating and deciding } \\
\text { upon the results of diagnostic investigations }\end{array}$ \\
\hline Weltanschauung/worldview & $\begin{array}{l}\text { A belief that multidisciplinary and patient-centred decision making } \\
\text { enables better diagnosis, treatment and care plans that lead to } \\
\text { improved patient outcomes }\end{array}$ \\
\hline Owner & MDT participants, Medway NHS Trust, Department of Health \\
\hline Environmental Constraints & $\begin{array}{l}\text { Clinical guidelines, physical and technological facilities available for } \\
\text { the meeting, MDT participants' timetable, patient target times }\end{array}$ \\
\hline The Es - performance measures & $\begin{array}{l}\text { Efficacy - Does the MDT meeting provide multidisciplinary and } \\
\text { patient-centred clinical decision making (diagnosis, treatment and a } \\
\text { care plan) for each patient? } \\
\text { Efficiency - Are the minimum resources used to obtain } \\
\text { multidisciplinary and patient-centred clinical decision making? } \\
\text { Effectiveness - Does multidisciplinary and patient-centred clinical } \\
\text { decision making lead to improved patient outcomes? }\end{array}$ \\
\hline
\end{tabular}

A primary task approach (mapping onto existing organisational boundaries) to SSM was adopted with an aim of arriving at a single purposeful activity model of the transformation. A purposeful activity model is roughly categorised as either primary task or issue based (Checkland, 1999b). Primary task models tend to represent the stakeholders' account of activity that is found in the real world organisation; issue based concern stakeholders' account of activity that does not necessarily map onto organisational boundaries but is activity relevant to the debate. In the authors' experience primary task purposeful activity models are often a mixture of both categories as stakeholders are encouraged to think beyond existing activities and put forward activities that could be there to support the transformation. 
J ournal of the Operational Research Society (2013) 64, 125- 137.

doi: 10.1057/jors.2012.21; published online 18 April 2012

During the workshop the SSM tool outputs (CATWOE, root definition and PAM) were debated and the necessary modifications were made in order to ensure that they are representative of the views of the MDT members regarding the optimal function and organisation of their meeting (Table 1 shows the final definitions). The PAM constructed during the workshop was considered to be by all those attending as something to aim for (Figure 3). It should be noted that, the definitions and transformation process provided here are relevant to and representative of the specific group of stakeholders' opinions and not relevant to other MDTs. Someone else's opinion or another MDT's opinion of the transformation might be different to the one held by our group of stakeholders. 


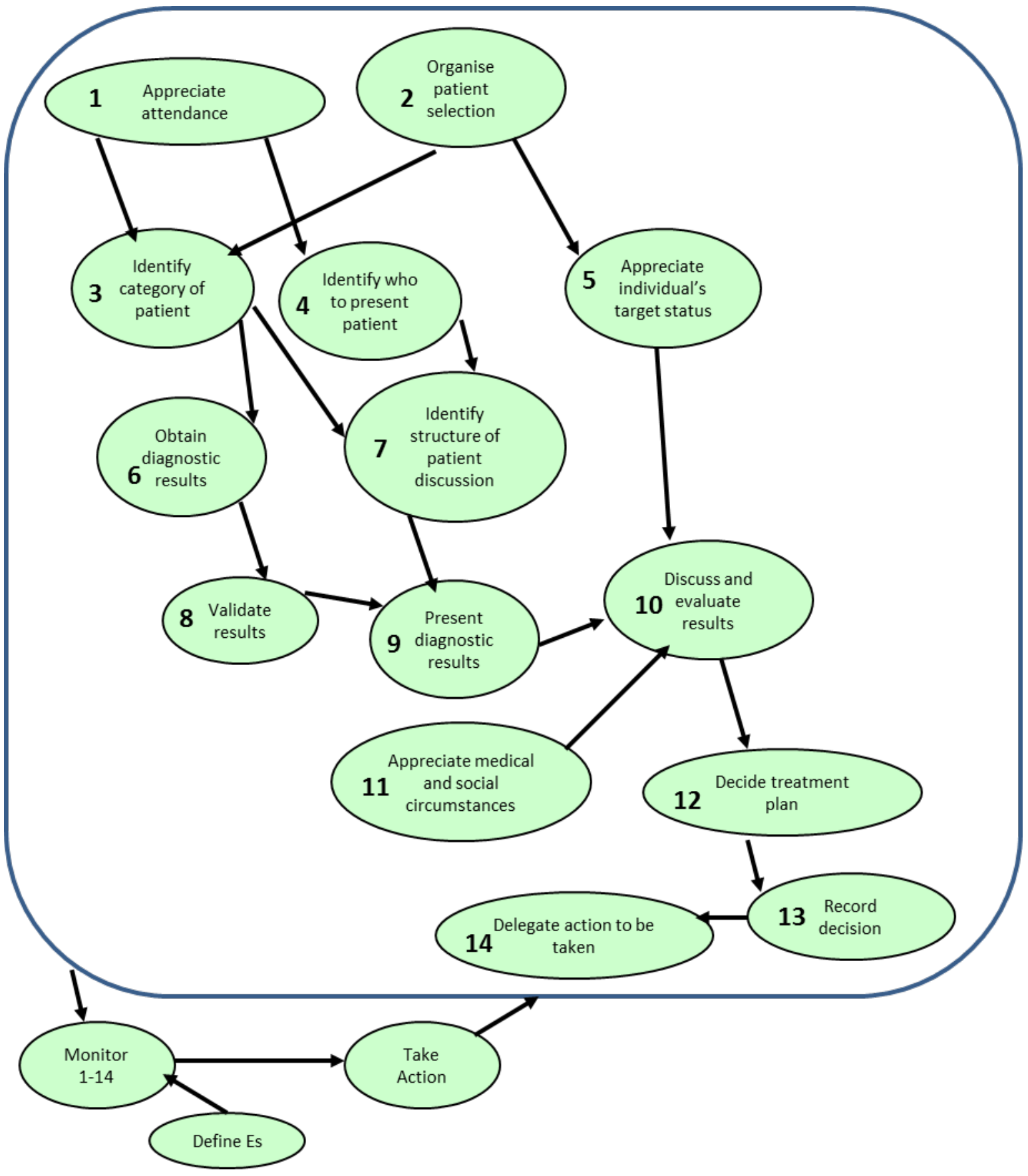

Figure 3 The MDT activities supporting the operational transformation

The discussions of the PAM activities brought forward issues that had not been previously discussed by the members, such as good practice found in other MDTs. It became apparent that the workshop was the first time that the group got together to discuss the functioning, as well as issues and problems of the MDT meetings. This meant that the allocated time for discussions of their activities was not enough to complete the SSM process. The 3Es (performance criteria) were not discussed in detail and we did not arrive at a clear list of actions (the fourth methodological step for SSM) with an expanded description on how each 
J ournal of the Operational Research Society (2013) 64, 125- 137.

doi: 10.1057/jors.2012.21; published online 18 April 2012

should be done or agree to a timeline for each implementation. However, a number of actions to be taken were proposed when the PAM activities were explored. The reader should note that the concept of using a PMM (Kotiadis, 2007) in standalone SSM studies had not been considered at the time the workshop in 2006 .

All the outputs developed at the first workshop were distributed to all MDT stakeholders to ensure that the workshop discussion was recorded correctly and that the definitions and the model were agreeable to all the members. The aim was to enhance stakeholders' memory of any action resulting from discussing the models and hence make it possible for action to be realised. However the responses to these outputs were few due to the participants' time constraints and/or perhaps because they did not have any amendments or additions to make.

\subsection{Incorporating a performance evaluation element to the MDT (Workshop 2)}

\subsubsection{Observations of MDT in 2009}

In 2009 the original OR analysts alongside additional analysts approached the MDT to revisit the original intervention that ended shortly after the workshop took place in 2006. The aim was to establish if any action had been taken since the first workshop and to explore if developing a PMM in a workshop environment would be useful to the SSM process. A subset of the analysts observed the MDT in action and it was immediately clear that several improvements (actions), in line with the discussions in the 2006 workshop, had been implemented.

The MDT meeting had been officially timetabled which meant that the team members were able to attend as there were fewer clashes with other duties. The meeting had moved to a much larger room with a separate area for the results of clinical investigations to be presented (projected) to the team. The seating in the room was arranged around a large Ushape table providing all members with the opportunity to listen and contribute to the discussions taking place. The team seemed to communicate effortlessly despite one of the key members, the oncologist, was communicating via a remote link (video conferencing). Prior to using the video conferencing facilities, the oncologist who was based at another 
J ournal of the Operational Research Society (2013) 64, 125- 137.

doi: 10.1057/jors.2012.21; published online 18 April 2012

hospital in the same region, used to arrive late or was not able to attend every meeting despite his best efforts. The meeting now also provided an educational value to middle and lower grade doctors and surgeons in training as the discussions and findings were easier to follow.

Having observed the radical improvement in the way the MDT was functioning, it was felt appropriate to follow up on the results of the original intervention. Unfortunately, because the results of soft interventions such as SSM are not easily quantifiable (White 2006; Connell 2001; Mingers et al. 2009), we could not establish or claim retrospectively that the action taken so far resulted from the first workshop. Hence, we invited the MDT participants to a second workshop in order to establish, among other things, if any further action had taken place that related to the discussions and outputs of that original workshop in 2006. Apart from understanding the extent to which the notional model, represented by the PAM (figure 3), had become real we also wanted to judge it using the performance measurement model put forward by Kotiadis (2007).

Both SSM interventions have been subject to the participants' strict time constraints and organised with the need to keep the workshop's duration to a minimum. On reflection from the original workshop and other experiences gained about clinicians' availability, a two hour workshop seemed to be enticing to them. In this strict time slot, we had to allow time for both exploring the action that had taken place since the first workshop and to model the performance measurement aspects.

To aid the process of constructing the PMM and to speed up the process of explaining what needed to be done during the workshop we constructed a simple performance measurement model (prior to the workshop) with few activities. Bringing preliminary models into a workshop is not a new idea as Andersen and Richardson (1997) have also advocated their use in group model building (system dynamics workshops) and they refer to these as very stripped-down concept models. This basic PMM was based on the PAM (operational function) developed in 2006 during the first intervention.

\subsubsection{Workshop 2 (2009)}


J ournal of the Operational Research Society (2013) 64, 125- 137.

doi: 10.1057/jors.2012.21; published online 18 April 2012

Workshop 2 was structured into six tasks. Task 1 was an individual brainstorming task (a pre-test) asking each of the participants to list three actions on a form that they thought should be undertaken to improve the performance of the MDT. The form was collected before proceeding to the next task. This task was also repeated towards the end of the workshop (referred to as task 5), using a second form (a post-test), which we aimed to use to assess the impact of the workshop process on their views. The second and third task aimed at establishing whether the outputs constructed three years earlier (table 1, figure 3 ) were still relevant. More specifically, task 2 was to revisit the root definition (a structured form of CATWOE) and establish if this was still a reasonable definition of the MDT operations. Task 3 was to revisit the PAM diagram (figure 3 ) for the operational aspect of the MDT and establish if there were activities that were not implemented and/or irrelevant. In order to achieve task 3 across all workshop participants without spending considerable amounts of time asking each person's view, we handed out a paper copy of the PAM to each participant and asked them to classify each activity as I) implemented, WT) still working towards and $\mathrm{NI}$ ) not implemented or irrelevant. Although we were only really interested in establishing if there were any activities classified as NI we felt we needed to include WT, as well as implemented (I) activities, as an input as we expected that participants' opinions may vary on whether an activity is fully established and working as it should. However, there would be little doubt as to whether an activity actually exists.

From those that filled in the PAM scoring form there was considerable disagreement on the status of each activity being implemented (I) or working towards (WT) (Table 2). Some of the participants did not score all of the activities (note the dashes in some cells in table 2). A possible explanation for this happening is the strict time constraints and/or their indecisiveness at choosing between (I) and (WT). This provides another argument as to the need of performance measurement as a form of evaluation. The submitted answers did not include any NI for the activities in the 2006 PAM and when the participants were asked if further activities should be added to the 2006 model, none were put forward. The participants unanimously agreed that the 2006 PAM was still relevant. In fact, activities 1 and 2 on the PAM of the operational function (figure 3) that received little attention in 2006 received particular attention in this workshop. 
J ournal of the Operational Research Society (2013) 64, 125- 137.

doi: 10.1057/jors.2012.21; published online 18 April 2012

Table 2. The participants' view of status of activities

\begin{tabular}{|c|c|c|c|c|c|c|c|c|}
\hline \multirow{2}{*}{\multicolumn{2}{|c|}{ Activity }} & \multicolumn{7}{|c|}{ participants } \\
\hline & & 1 & 2 & 3 & 4 & 5 & 6 & 7 \\
\hline $\begin{array}{l}\text { Appreciate } \\
\text { attendance }\end{array}$ & activity 1 & WT & 1 & - & I & WT & I & - \\
\hline $\begin{array}{c}\text { Organise patient } \\
\text { selection }\end{array}$ & activity 2 & 1 & 1 & I & 1 & - & 1 & - \\
\hline $\begin{array}{c}\text { Identify category of } \\
\text { patient }\end{array}$ & activity 3 & 1 & 1 & I & I & - & I & - \\
\hline $\begin{array}{l}\text { Identify who to } \\
\text { present patient }\end{array}$ & activity 4 & 1 & 1 & I & WT & WT & I & - \\
\hline $\begin{array}{c}\text { Appreciate } \\
\text { individual's target } \\
\text { status }\end{array}$ & activity 5 & WT & 1 & 1 & I & - & WT & WT \\
\hline $\begin{array}{l}\text { Obtain diagnostic } \\
\text { results }\end{array}$ & activity 6 & WT & 1 & WT & I & - & WT & - \\
\hline $\begin{array}{l}\text { Identify structure of } \\
\text { patient discussion }\end{array}$ & activity 7 & WT & 1 & - & WT & - & 1 & - \\
\hline Validate results & activity 8 & 1 & 1 & I & I & - & - & - \\
\hline $\begin{array}{c}\text { Present diagnostic } \\
\text { results }\end{array}$ & activity 9 & 1 & 1 & WT & 1 & - & WT & - \\
\hline $\begin{array}{c}\text { Discuss and evaluate } \\
\text { results }\end{array}$ & activity 10 & 1 & - & I & 1 & WT & WT & - \\
\hline $\begin{array}{c}\text { Appreciate medical } \\
\text { and social } \\
\text { circumstances }\end{array}$ & activity 11 & WT & 1 & 1 & I & - & I & WT \\
\hline Decide treatment plan & activity 12 & 1 & 1 & WT & I & WT & I & - \\
\hline Record decision & activity 13 & 1 & 1 & WT & I & - & I & - \\
\hline $\begin{array}{c}\text { Delegate action to be } \\
\text { taken }\end{array}$ & activity 14 & 1 & I & WT & I & - & WT & WT \\
\hline
\end{tabular}

I: implemented; WT: working towards; NI: not implemented or irrelevant, '-': participant did not classify the activity.

The activity 'appreciate attendance' was of particular interest as the histopathologist had some absences due to reductions in staffing (from 4.5 full time equivalent down to 1 ) resulting in the cancelation of the MDT meeting on those occasions. The minimum number of attendants or specialties present to achieve quorum was discussed at length. Many ideas were put forward including recording on their official documentation whether the MDT opinion on a case is "valid or complete". The educational benefit for trainee doctors and surgeons of specialist participation was also touted.

In terms of the activity 'organising patient selection', the participants mentioned some instances in which the surgeon did not see (although the patient had been seen by others) the patient before the case was discussed at the MDT. The surgeons argued that seeing the patient is extremely important as a relationship of trust can be built between surgeon and patient. Also, the surgeon can acquire a much more informed opinion on the general health 
Journal of the Operational Research Society (2013) 64, 125-137.

doi: 10.1057/jors.2012.21; published online 18 April 2012

and condition of the patient. Interestingly in task 3 (Table 2 ) the responses to these PAM activities on the whole were that they had been implemented (I) or they were working towards these (WT). This discussion of the activities in the PAM supports the need for an evaluation of all the activities contributing to their operational function in a more formal and structured manner to pick up issues such as these. The construction of a PMM model (task 4) provides this opportunity.

Task 4 was to construct a performance measurement model (PMM). As explained earlier a preliminary PMM with very few activities was shown to the participants in order to explain its structure. The workshop participants were told that the activities shown in the PMM were not necessarily correct but would give them an idea of how to construct these. Bringing a preliminary model into the workshop would also help in speeding up the process of constructing it. It should be noted that in our intervention, half the workshop time was dedicated to this task (task 4). The workshop participants were also provided with guidance on how to construct the PMM based on some of the guidance suggested by Kotiadis (2007):

1. Find out how the performance criteria (3Es, defined in Workshop 1) developed relate to the real life situation. Reflect on how each activity, supporting the transformation process in the PAM, can be evaluated.

2. Break down the performance criteria (3Es) into specific monitoring activities, which are activities that involve observing and recording information. Where possible these activities should be in the format 'monitor...'.

3. Consider what action might be taken based on each of the monitoring activities or their combinations. Where possible record this action in the format 'determine if...'.

4. Where possible try and list the monitoring activities first and then link them according to logical dependencies to the 'determine if' activities. Similar to the core PAM, circle each activity in the PMM and if helpful assign each a letter of the alphabet (rather than a number used in the core PAM).

The participants were encouraged to consult the PAM and consider what information they would want to monitor for each activity or for a group of activities and what they would/could determine from that monitoring action or group of monitoring actions. The 
J ournal of the Operational Research Society (2013) 64, 125- 137.

doi: 10.1057/jors.2012.21; published online 18 April 2012

examples provided on the preliminary PMM acted as a starting point to the task but the participants soon engaged in conversation and were engrossed thereafter in relevant discussion without encouragement from the facilitators. The facilitators recorded the monitoring activities during the first part of this task with as few as possible interruptions so as not to hinder the trails of thought put forward by the participants. Any interruptions to the conversation were to clarify the wording of the activities in the model. The 'monitoring' activities were then used to derive the 'determine if' activities. The PMM activities were then linked and reorganised after the workshop to ensure the minimum crossover of links. The PMM constructed as a result of the workshop can be seen in Figure 4.

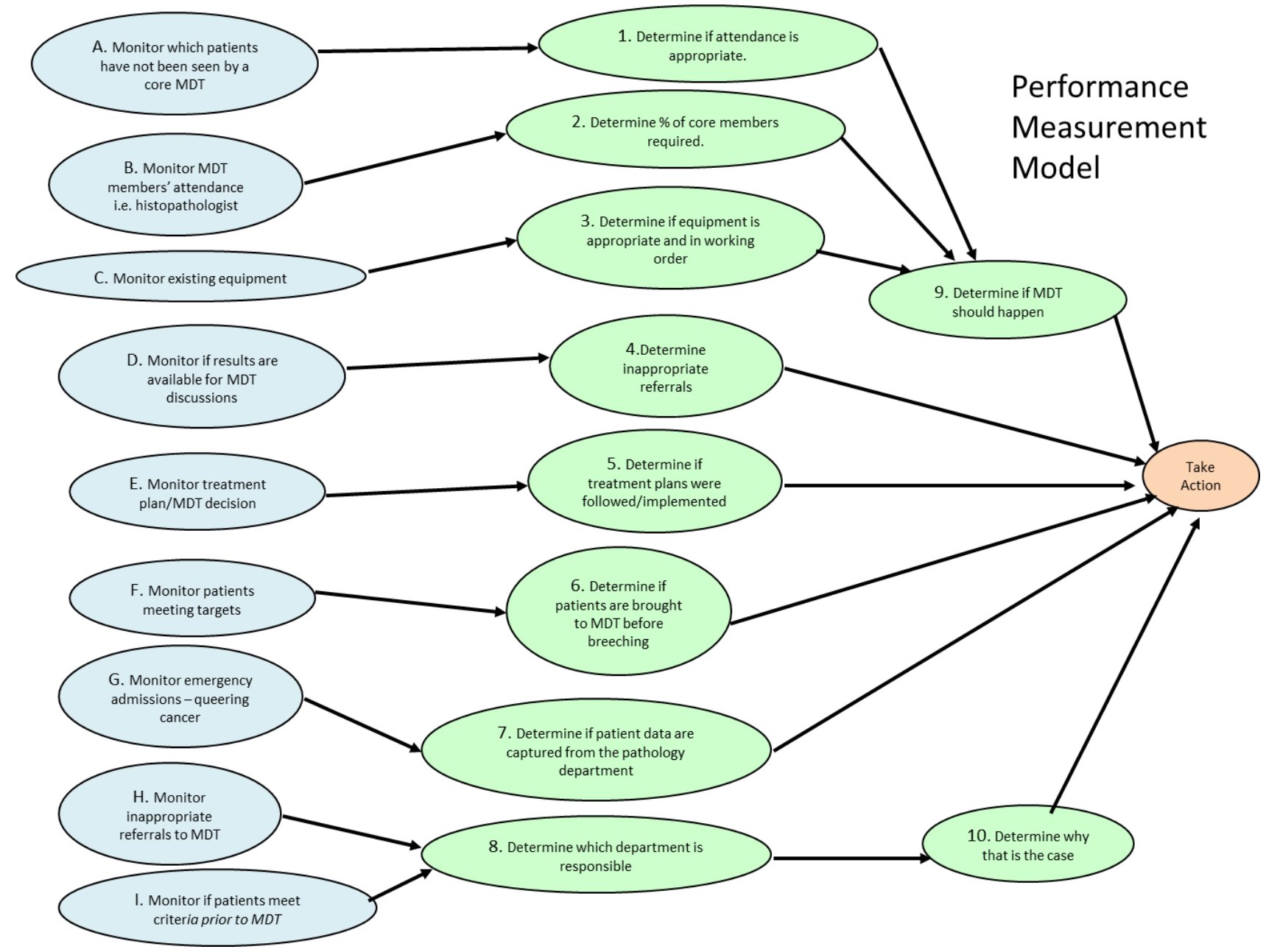

Figure 4 The performance measurement model supporting the operational transformation process of the MDT

Task 5 was to ask each of the participants to list three actions on a form (a post-test) that should be undertaken to improve the performance of the MDT. Task 5 also provided a warm up exercise to task 6 that was to get the participants collectively to discuss what action (if 
J ournal of the Operational Research Society (2013) 64, 125- 137.

doi: 10.1057/jors.2012.21; published online 18 April 2012

any) should be taken based on the PMM. However many actions had already been partly discussed whilst constructing the PMM. The participants were subsequently asked to consider action that would be implemented in the short term (three to six months) and longer term. The participants came up with three actions to be undertaken in the short term and were keen to create a system of evaluation that captured all the activities in the PMM for the longer term. This short term action, which resulted from discussing activities $A, G, H$ in the PMM, included the following:

- The colorectal firms would liaise with other general surgery firms on-call to capture the emergency patients with a query for colorectal cancer. It was suggested that the surgical firm could contact the on-call team (if other than a member of the colorectal surgeons), or the surgeons to check the operating theatre lists for any relevant emergency activity.

- To record inappropriate referrals to the MDT. This would be done by the colorectal nurse who would monitor the number of inappropriate referrals (i.e. patients that have not been seen by a colorectal nurse).

- The MDT attendance would be recorded on the official documentation used for the organisation of the MDT meeting.

\section{Discussion}

This paper set out to describe how the performance measurement model was used to enhance an SSM intervention in a real life case study. A particular feature of the intervention reported here is that the approach was participative by involving stakeholders in a workshop environment. We have attempted to provide a transparent way of using performance measures in identifying action as part of an SSM intervention so that outsiders can follow the research in order to critically scrutinise it. This is in line with Checkland's (1999b) assertions on how action research should be conducted.

Reflecting on the overall intervention undertaken, a few issues need to be further considered such as factors influencing the success of the study and whether the study was deemed to be successful.

Even though our contribution mainly concerns the second workshop, we first briefly refer to the first workshop, as it was the predecessor and we believe that it had an effect on the second workshop. Although we cannot claim retrospectively that an improved MDT function witnessed in 2009 is down to that first facilitated workshop there are two factors that 
J ournal of the Operational Research Society (2013) 64, 125- 137.

doi: 10.1057/jors.2012.21; published online 18 April 2012

should be taken into account. First, the MDT participants remained largely the same individuals between the first and second workshop which decreases the possibility of external influences. Second, the improvements to the MDT function were not recent and had been established in the first half of the three years following the first workshop. Therefore, the first workshop is considered a positive predecessor and influence on the second workshop. We believe this is the case as the majority of the MDT membership attended the first and second workshop that took place outside their remunerated hours. This also indicates their commitment to improving their MDT and the trust held for the operational researchers.

A number of factors that may have an influence on the success or the way any SSM study is undertaken can be circumstantial, including for example, facilitation, personality, relationship between the analysts and the stakeholder team, the availability of the stakeholder team. Facilitation, which involves one (or more) of the analyst team leading the discussion, is a key factor for the achievement of the suggested steps and the intervention overall. The facilitator can have a personal impact on the intervention and can in fact influence its success or not, for instance, a poor facilitator can allow the conversation to lose focus and waste valuable workshop time (Papamichail et al, 2007). Understandably, for each SSM intervention the facilitator is chosen depending on the membership of the team of analysts, however some personal characteristics and skills (conflict handling, challenging stakeholders' mindsets, integrity etc) set out in more detail in Vennix (1999) ought to be considered. Of course, these factors cannot be fully controlled in an SSM intervention, but on the whole can be evaluated. On reflection of this intervention the role of the facilitator was taken by one individual within the team for reasons of continuity and because of that person's background knowledge of the MDT but the organisation of the workshop into tasks was a team activity (analysts). It would be difficult to comment on personalities but we can comment on the other circumstantial factors such as our relationship with the stakeholders was very good, with proof again being their continued engagement in the second workshop.

We will continue to reflect on the success of the intervention by exploring the following questions:

- Was the PMM useful? 
Journal of the Operational Research Society (2013) 64, 125-137.

doi: 10.1057/jors.2012.21; published online 18 April 2012

- When and how to use a PMM within SSM

\subsection{Was the PMM useful?}

Connell (2001) suggests different perspectives for establishing the success of an intervention using SSM. The approach can be said to be successful if it helped to gain insight or manage change. Establishing an impact on these dimensions, and especially linking these to the intervention, is challenging. It would seem logical to ask participants on perceived impacts and whether these originated from being part of the intervention. However, participants may not be aware of changes in insight or actions and how these were caused. A line of studies in psychology show that people have little insight into whether they have learned and what caused learning (Nisbett and Wilson, 1977; Wilson, 2002). Instead of directly asking patients on changes in insight of action, Rouwette et al (2009) suggest to assess insights before and after the intervention. Therefore, during this study participants' insights were sought at the start and end of the second workshop to assess the impact of the process on their views. More specifically, the participants were asked to write down actions that could be undertaken to improve the performance of the MDT that would ultimately help us identify whether the process of deriving the PMM and the discussions following had an impact on participants' views (task 1 and 5 in workshop 2).

Overall, six participants completed the form for tasks 1 and 5 on actions to be taken, both before and after the workshop, resulting in 18 actions reported at both times. Examples of actions are 'Ensure complete attendance of all core members' and 'Typing on MDT proforma (official meeting document) must be projected and signed off by the whole team during MDT meeting - to avoid any errors'. In order to judge changes in opinions from pretest (task 1 ) to post-test (task 5 ), the three first authors estimated changes in all 18 actions. In five instances estimations differed but they settled on a decision after discussion. For estimating the similarity of post-test actions to activities proposed in the workshop, the scores of the two first authors (who due to their longstanding relation with the client organisation are familiar with the topics discussed) were used. Both authors scored the activities suggested regarding their perceived relevance to the activities in the PAM and PMM respectively. The scores of both authors differed in 0 and 6 instances respectively regarding the PAM and the PMM. The differences were again resolved through discussion. Of the 18 actions, 13 had changed from pre-test to post-test, aligning more to the activities 
J ournal of the Operational Research Society (2013) 64, 125- 137.

doi: 10.1057/jors.2012.21; published online 18 April 2012

of the PAM and PMM. Out of these 18 post-test activities, 16 referred to activities proposed in the PMM (Figure 4) and 12 to activities in the PAM (Figure 3). Activities that were mentioned most often (by two or more participants) in the post-test are appreciate attendance, organise patient selection and identify structure of patient discussion. Not surprisingly these were also the actions that the group agreed to take forward during task 6 (group discussion of future actions). Therefore this leads us to believe that:

- The process has led the participants to individually arrive at similar future actions (task 5). More importantly the responses were from a representative mixture of doctors, nurses and coordinators demonstrating that regardless of power, personal agendas and seniority they arrived at similar views.

- The process has led to group consensus on the key actions that need to be taken to improve the MDT (task 6).

If task 5 was not undertaken one might think that the final actions agreed to (task 6) may have been representative of one or two participants rather than the whole group. By examining the responses provided in the brainstorming exercise (task 5 section 3.3.2) one can clearly see that the individual opinions match the future actions to be taken resulting from task 6 . Therefore we would argue that the process leads to group consensus.

\subsection{When and how to use a PMM within SSM}

In this paper the SSM mode of practice described can be summarised using Figure 5. Understanding the problem situation using analysis One, Two and Three were undertaken mainly through the observations of the MDT in action and interviews of the MDT participants (Checkland's (1999b) SSM stage 1). The first facilitated workshop (2006) aimed to define the MDT function, discuss it and decide what action should be taken (Checkland's (1999b) SSM stages 2-4). At the end of workshop 1 the stakeholders had designed an improved MDT function but did not have the time during the workshop to discuss action to be taken to the extent that the OR analysts would be satisfied. Nevertheless we are incorporating SSM's stage 4 in this mode to the first facilitated workshop because as we have argued earlier the first workshop was positively viewed by the MDT membership and, in the time elapsing between the two workshops, they had taken action to improve their operational function that could be to some extent attributed to the first workshop. 
J ournal of the Operational Research Society (2013) 64, 125- 137.

doi: 10.1057/jors.2012.21; published online 18 April 2012

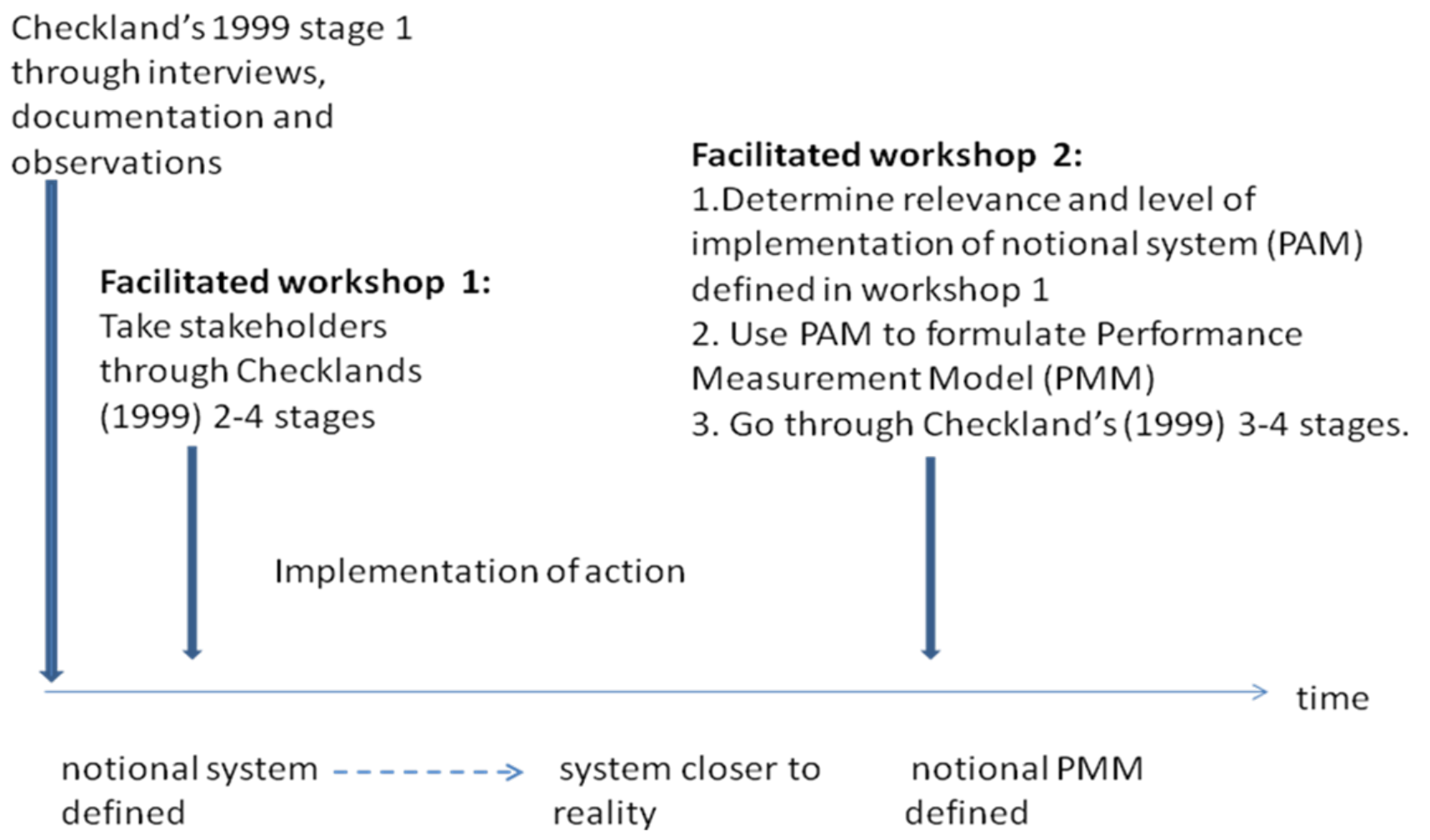

Figure 4 SSM with expanded performance measurement in practice across two workshops

The main aim of the 2009 facilitated workshop was to test out the idea of a PMM in a standalone SSM study. However, the PMM is reliant on the construction of a relevant PAM so we needed to agree that the 2006 PAM was relevant, modify it or change it altogether for something else. Therefore in workshop two we revisited SSM's stage 3 (Chekcland's, 1999b). In our case it was still relevant, which made it possible within the time constraints of that workshop to formulate the PMM and also use it for debate (Checkland's (1999b) stage 3) and then based on this debate to suggest action to be taken (Checkland's (1999b) stage 4). It should be noted that the PMM is notional and if we went back in 3 years from now we could complete the action research loop.

If the PAM in workshop 2 had needed modifications or had to be changed, then that would have taken precedence over the construction of a PMM. However a time lag is not necessarily needed between the development of the PAM and the development of the PMM. The benefit of the original time lag ( 3 years) was that the system was more 
J ournal of the Operational Research Society (2013) 64, 125- 137.

doi: 10.1057/jors.2012.21; published online 18 April 2012

established in 2009 (matching the original SSM outputs) and that made judging its performance more relevant to the stakeholders. However it is equally likely that if we had thought of the PMM in standalone SSM studies back in 2006 we could have also defined it. Therefore we believe that there are two modes of practice when integrating the PMM in the SSM cycle for primary task models. The first mode can be the one we put forward in the case study; formulate the PAM, allow for it to be implemented so judgement becomes more important and then formulate the PMM. In this mode the PMM can be used to evaluate the system as represented in the PAM and to debate the situation so that further action to be taken is identified. The second mode of practice is to formulate both the PAM and PMM and discuss them concurrently to decide on action to be taken. However further research is welcome to address the following questions:

Does the suggested second mode of practice work?

Does the PMM work with other groups of analysts for other problem situations?

Does the PMM fit with an issue based approach to SSM?

\section{Conclusion}

Given the importance of SSM's measures of performance, Bergvall-Kareborn and Grahn (1996) rightly suggest that there should be more transparency and guidance on how a novice user of the methodology can establish if these criteria are actually met by the system. It is not surprising that these questions have arisen about the measures of performance as in practice they are only broadly defined, usually after the CATWOE definitions, and could be ignored by many thereafter as they do not feature in any real detail in the purposeful activity models. Also in many interventions, even if a primary task SSM mode is adopted (mapping onto existing organisational boundaries) a considerable part of the model is notional so judging its performance may not be considered initially as important as defining it, as is the case study described in this paper. However, a system initially defined by SSM as a notional system, over time can be fully or partially adopted by the system owners; after all SSM aims to bring about action. Therefore the importance of these measures of performance can increase when the system is implemented (partially or fully) and more likely to benefit from evaluation. In this paper we have demonstrated the 
J ournal of the Operational Research Society (2013) 64, 125- 137.

doi: 10.1057/jors.2012.21; published online 18 April 2012

benefits gained by engaging with a group of stakeholders in building a model of the performance measures, called the performance measurement model, which can be used to evaluate the problematic situation represented in the PAM and to identify action to be taken as part of an SSM intervention. We hope that others adopt the approach fully or partly and report their findings in the literature in an effort to increase transparency in this part of the SSM practice.

\section{ACKNOWLEDGEMENTS}

Part of this research was funded by the Warwick Business School Research and Development Fund RDF (The University of Warwick).

\section{References:}

Andersen DF and Richardson PG (1997). Scripts for group model building. System Dynamics Review 13 (2): 107-129.

Bergvall-Kareborn B and Grahn A (1996). Expanding the framework for monitor and control in soft systems menthodology. Systems Practice 9 (5) 469-495.

Brignall S and Modell S (2000). An institutional perspective on performance measurement and management in the 'new public sector', Management Accounting Research, 11(3), 281306.

Carter S, Garside P, and Black A (2003). Multidisciplinary team working, clinical networks, and chambers; opportunities to work differently in the NHS. Qual Saf Health Care 12(1): 2528.

Checkland P, Forbes $\mathrm{P}$, and Martin S (1990). Techniques in soft systems practice part 3: Monitoring and control in conceptual models and in evaluation studies. Journal of Applied Systems Analysis 17: 29-37.

Checkland P (2006). Reply to Eden and Ackermann: Any future for problem structuring methods? J Opl Res Soc 57(7): 769-771.

Checkland P ( 1999a). Systems thinking systems practice. Wiley: Chichester.

Checkland $\mathrm{P}$ (1999b). Soft systems methodology: A 30-year retrospective. Soft systems methodology in action. P. Checkland and J. Scholes. Chichester, Wiley.

Connell NAD (2001). Evaluating soft OR: some reflections on an apparently 'unsuccessful' implementation using a Soft Systems Methodology (SSM) based approach. J Opl Res Soc 52: 150-160. 
J ournal of the Operational Research Society (2013) 64, 125- 137.

doi: 10.1057/jors.2012.21; published online 18 April 2012

Eden C and Ackermann F (2006). Where next for problem structuring methods. J Opl Res Soc 57(7): 766-768.

Kaplan R S and Norton D P (2001). Transforming the Balanced Scorecard from Performance Measurement to Strategic Management: Part I. Accounting Horizons, 15(1), 87-104

Kotiadis K (2007). "Using soft systems methodology to determine the simulation study objectives." Journal of Simulation 1: 215-222.

Lewin K, (1946). Action Research and minority problems. Journal of Social Issues, 2:34-46.

Lohman C, Fortuin L, and Wouters M (2004). Designing a performance measurement system: A case study. European Journal of Operational Research, 156(2), 267-286.

Mingers J, Liu W and Meng W (2009) Using SSM to structure the identification of inputs and outputs in DEA. J Opl Res Soc 60:168-179.

Nisbett R and Wilson T (1977). Telling more than we can know: Verbal reports on mental processes. Psychol Rev 84(3): 231-259.

Papamichail K N, Alves G, French S, Yang JB and Snowdon R (2007). Facilitation practices in decision workshops. J Opl Res Soc 58(5): 614-632.

Rouwette EAJA, Vennix JAM and Felling AJA (2009). On evaluating the performance of problem structuring methods: an attempt at formulating a conceptual model. Group Decision and Negotiation: 18(6): 567-587.

Vennix JAM (1999). "Group model-building: tackling messy problems." Sys Dyn Rev 15(4): 379.

Westcombe M, Franco LA and Shaw D (2006). "Where next for PSMs - A grassroots revolution?" J Opl Res Soc 57(7): 776-778.

White L (2006). Evaluating problem-structuring methods: developing an approach to show the value and effectiveness of PSMs. J Opl Res Soc 57: 842-855.

Wilson T (2002). Strangers to Ourselves, Discovering the Adaptive Unconsciousness. Harvard University Press: Cambridge, MA. 